\title{
Modelo de estudo das spin-offs de uma incubadora de empresas de base tecnológica
}

\author{
Bárbara Emanuelle de Carvalho Minardi \\ barbara.minardi@ufv.br
}

\section{Flávio Lúcio Martins Vita}

flavio.vita@ufv.br

Jaqueline Akemi Suzuki

jaqueakemi@hotmail.com

Frederico Souza Lima Bittencourt de Souza

fredbittencourt@ufv.br

Adriana Ferreira de Faria

adrianaf@ufv.br

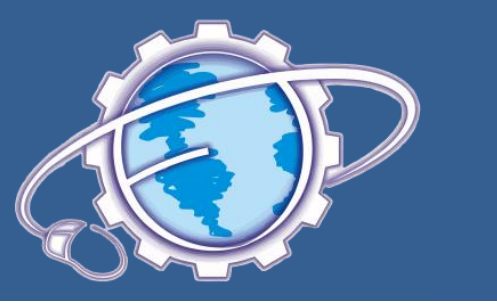

\section{RESUMO}

Para que um país atinja um nível melhor de condições sociais e econômicas são imprescindíveis o desenvolvimento e amadurecimento do processo de inovação, que normalmente envolve as instituições de pesquisa, empresas e governo. O berço da geração de conhecimento se dá através de pesquisas realizadas dentro das universidades e centros de pesquisa. Espera-se que os resultados das pesquisas aplicadas para este estudo possam fomentar a criação de empresas de base tecnológica que possibilitam a geração de empregos altamente qualificados, geram divisas para a sociedade e criam maior dinâmica inovativa para a indústria nacional. Assim, devido à importância dessas empresas para a sociedade, este trabalho teve por objetivo geral estudar o desempenho de empresas de bases tecnológicas de origem acadêmica, as chamadas spin-offs acadêmicas. As empresas analisadas representam amostra daquelas que participaram do programa de incubação de uma incubadora de empresas de base tecnológica, pertencente a uma grande universidade do país.

Palavras-chave: Empresas nascentes de base tecnológica; Gestão da inovação; Incubadora de empresas de base tecnológica.

\section{Model study of the spin-offs of an incubator for technology-based companies}

\begin{abstract}
A country, in order to reach a better level of social and economic conditions, must have development and maturation in the innovation process, which generally involves research institutions, private enterprises, and government. The source of knowledge generation occurs through research programs conducted at universities and research centers. It is expected that the results from the research programs applied to this study may enhance the creation of technology bases companies, which would enable the implementation of highly qualified jobs, generate new frontiers to society and create a larger innovative dynamics for the national industry. Thus, because of the importance of these businesses to society, this study has the objective to evaluate the performance of the technology bases companies of academic origin, the so called spin-offs academic enterprises. The analyzed businesses represent a sample of those which have participated in the technological based incubator program from a well known brazilian university.
\end{abstract}

Key words: Start up; Innovation Management; Incubator for Technology-Based Companies. 


\section{Introdução}

Com vistas a promover o desenvolvimento econômico e social do país, várias iniciativas vêm sendo realizadas dentro do contexto das universidades brasileiras, com o intuito de fomentar a criação de empresas de base tecnológica a partir de pesquisas acadêmicas inovadoras. Tais empreendimentos, também conhecidos como spinoffs acadêmicas, são caracterizados por explorar a propriedade intelectual desenvolvida em instituições acadêmicas, criando valor econômico para o mercado, gerando empregos de alta qualificação e promovendo o desenvolvimento de produtos e negócios inovadores

Segundo Sanchéz e Pérez (2000 apud COSTA, 2006), as empresas criadas pelos acadêmicos constituem importante elemento dinamizador de uma economia não tanto pelo emprego direto que podem chegar a criar, mas porque supõem o desenvolvimento de novos setores industriais ou de serviços e porque, com sua transferência de tecnologia, contribuem para melhorar a competitividade de outros setores. Assim, as spin-offs acadêmicas vêm ganhando espaço nos últimos anos, pois elas criam uma nova dinâmica para o processo de desenvolvimento de um país, trazendo à sociedade conhecimentos que, muitas vezes, ficavam restritos ao meio acadêmico, gerando avanços sociais por meio da criação de empregos e proporcionando melhorias econômicas ao produzir divisas para o Estado (COSTA, 2006).

Para Araújo et al. (2005), as Empresas Nascentes de Base Tecnológica (ENBTs) têm grande impacto, especialmente, no desenvolvimento econômico local, pois normalmente geram alto valor econômico, manufaturando produtos inovadores de alto valor agregado e satisfazendo necessidades e desejos de clientes específicos e diferenciados; proporcionam empregos, especialmente, para a população de maior grau de instrução; induzem o investimento no desenvolvimento de pesquisa, favorecendo o surgimento de novas tecnologias; e têm impacto econômico fortemente localizado, com importância na economia local.

Cheng et al. (2005) consideraram, dessa forma, ENBTs as empresas do futuro, e o empreendedorismo tecnológico vem sendo apontado como forte aliado do desenvolvimento econômico e social de regiões e países. $\mathrm{O}$ auxílio ao surgimento dessas empresas não se limita somente às políticas e aos programas de incentivos, mas engloba também um suporte técnico aos empreendedores. Segundo Mustar et al. (2006), as ENBTs enfrentam basicamente dois problemas durante a sua criação, são eles: 1) o empreendedor geralmente está inserido em um ambiente universitário, que não possui habilidades comerciais para criar empreendimentos viáveis; 2) o empreendimento, ao se inserir no mercado, é afetado por objetivos conflitantes das partes envolvidas, a exemplo da universidade, do empresário acadêmico, da equipe de gestão e dos fornecedores de capital.

Para Faria et al. (2008), a alternativa que oferece infraestrutura educacional e científica, mecanismos de apoio à inovação e cooperação tecnoloógica necessários para empreendimentos inovadores em estágio inicial, pode ser oferecido através das incubadoras de empresas, em que estas encontram ambiente que favoreça o desenvolvimento de suas competências, tornando-as sustentáveis e competitivas num cenário nacional e internacional.

Uma incubadora de empresas é um local especialmente criado para abrigar empresas oferecendo estrutura configurada para estimular, agilizar ou favorecer a transferência de resultados de pesquisa para atividades produtivas. Para isso, a incubadora oferece apoio gerencial e técnico (serviços de recepção e secretaria, salas de reunião, internet, telefone etc.) e uma gama de serviços que propiciam excelentes oportunidades de negócios e parcerias, para que se desenvolva o projeto/empresa (ANPROTEC, 2010). Por meio das incubadoras de empresas, os problemas gerenciais de empresas em estágio inicial são solucionados em conjunto, pois a maioria desses problemas se refere a dificuldades de planejamento, acesso a capital e desconhecimento das habilidades necessárias ao empreendedor para obter sucesso, que são esclarecidos dentro do ambiente das incubadoras de empresas (DORNELAS, 2002).

Nesse sentido, devido à dificuldade no desenvolvimento de ENBTs e à importância dessas empresas para a sociedade, este trabalho teve por objetivo geral estudar o desempenho de empresas de base tecnológicas de origem acadêmica, as chamadas spin-offs acadêmicas. As empresas analisadas representavam a amostra daquelas que participaram do programa de incubação de uma incubadora de empresas de base tecnológica pertencente a uma grande universidade do país. 


\section{Referencial teórico}

As relações entre ciência e desenvolvimento tecnológico visando à geração de riqueza e desenvolvimento econômico e social têm sido tema central nos estudos sobre ciência, tecnologia e inovação. Diversos teóricos evolucionários têm apontado a ciência e tecnologia como fatores cruciais para o desenvolvimento econômico e industrial, remetendo, com frequência, à grande importância da interação entre universidades e empresas (LEMOS, 2008). De acordo com Costa (2006), a inovação tecnológica é um dos pilares da competitividade das empresas e, juntamente com o conhecimento científico e a tecnologia, forma a base para o desenvolvimento econômico das nações.

Segundo Lemos (2008), na abordagem do sistema nacional de inovação os responsáveis pela geração de inovações são: universidades e instituições de pesquisa, empresas e governo. A universidade contribui para o progresso técnico do setor produtivo, principalmente com o conhecimento científico e a formação de recursos humanos, além de incentivar a criação de empresas formadas por acadêmicos e formar pessoal capacitado para fundar novas empresas (acadêmicos empreendedores). Por sua vez, as empresas transformam os conhecimentos em bens para a sociedade, gerando também, por meio das necessidades inerentes ao processo produtivo, novas demandas científicas às universidades. Por fim, o governo é responsável pela regulação, fiscalização e elaboração de políticas de apoio à interação entre esses atores.

A transferência de tecnologia das universidades para o setor privado contribui significativamente para a criação de novos negócios e de novos empregos, promove avanços tecnológicos e leva ao aumento da riqueza social, isso porque o conhecimento só gera valor $\mathrm{e}$ benefícios sociais quando é transferido de seu meio de produção para a sociedade (HARMON et al., 1997 apud COSTA, 2008). Através dessa transferência, ao longo dos anos a universidade desenvolveu e aperfeiçoou seus mecanismos de interação com a sociedade. A pesquisa básica e a formação de recursos humanos passaram a atuar em conjunto com outras formas de transferência do conhecimento, visando atender a uma nova dinâmica econômica e tecnológica.

Entre os diversos conceitos de tecnologia e de sua transferência surge uma nova ênfase focada nas formas de transferir conhecimento e tecnologia gerados nas universidades para o setor produtivo e, assim, alcançar maior impacto no desenvolvimento econômico do país. Esse novo enfoque implica ampliação das relações de colaboração entre universidades e empresas, intensificando o processo de transferência de novos conhecimentos e tecnologias avançadas, acelerando a venda de direitos ou o licenciamento de patentes resultantes de pesquisas acadêmicas e o surgimento de spinoffs acadêmicos (AZEVEDO, 2005).

A universidade passa a assumir, assim, papel destacado no processo de inovação devido à importância crescente do conhecimento como base para a produção de novos produtos, processos e serviços na economia moderna. Além disso, os estudos sobre o aprendizado e as inovações tecnológicas revelam que os processos de aprendizagem têm papel decisivo na mudança técnica e são influenciados pelas formas institucionais da economia (LUNDVALL, 1988; ROSENBERG, 1982; LEVINTHAL, 1996 apud LEMOS, 2008).

Uma das mais importantes contribuições das universidades para a sociedade são as spin-offs, nas quais acadêmicos individualmente ou suas instituições como um todo formam uma companhia separada para explorar e comercializar a Pesquisa e Desenvolvimento ( P\&D) (COSTA, 2006). O conceito de spin-off acadêmica é bastante diversificado na literatura técnica. Algumas definições são mais restritivas, e outras utilizam conceitos mais abrangentes e, normalmente, abordam ao menos um dos três pontos: (i) a tecnologia ou conhecimento que de, alguma forma, deu origem à empresa; (ii) os fundadores; e (iii) a participação societária da universidade na empresa ou seu financiamento público.

Ndonzuau et al. (2001) definiram spin-offs acadêmicas como o processo de transformação dos resultados de pesquisas acadêmicas, advindas de laboratórios das universidades, em tecnologia para o desenvolvimento de produtos e negócios. Ademais, Shane (2004 apud PEREIRA, 2007) conceituou spin-offs acadêmicas como "novas empresas fundadas para explorar um item de propriedade intelectual criado em uma instituição acadêmica".

Para Brisolla (1998 apud COSTA, 2006), “a spin-off é um processo mediante o qual pesquisadores acadêmicos geralmente como fruto de uma atividade de pesquisa que lhes parece promissora do ponto de vista prático, aventuram-se a assumir o papel de empresário ou associam-se a 
empresários interessados em assumir o risco de transformar sua ideia ou resultado de sua pesquisa em produto. Geralmente, isso é acompanhado pelo afastamento do cientista das universidades de origem ou pela redução de sua dedicação ao trabalho acadêmico".

A criação das spin-offs, segundo Costa (2008), tem-se tornado um caminho cada vez mais natural para o aproveitamento de resultados de pesquisas científicas. Os motivos que levam à sua formação são: a possibilidade de colocar no mercado uma tecnologia gerada, cuja transferência por outro meio é menos trivial; e a expectativa de obter ganhos financeiros.

Roberts e Malone (1996 apud PEREIRA, 2007) identificaram três papéis principais no processo de criação de uma spin-off: i) originadora da tecnologia: a pessoa ou organização que faz a tecnologia da pesquisa básica passar por estágios de desenvolvimento até o ponto de ser transferida; ii) a organização-mãe: o P\&D é conduzido pelo originador da tecnologia, o qual assiste e controla o processo de proteção intelectual por intermédio do escritório de transferência de tecnologia e cria um negócio centrado na referida tecnologia; e iii) o investidor: aquele que representa a empresa de capital empreendedor que fomenta o empreendimento em troca da participação acionária na nova empresa.

Como apresentado por Ndonzuau et al. (2001), o processo de criação de uma spin-off acadêmica pode ser dividido em quatro etapas principais: 1) geração de ideias a partir de resultados da pesquisa; 2) finalização de projetos do novo negócio a partir das ideias; 3) lançamento da spin-off; e 4) fortalecimento da nova empresa. Nesse modelo, cada um dos estágios tem função específica no processo de criação de spin-offs. A primeira etapa gera e avalia ideias com respeito à possibilidade de comercialização. A segunda etapa considera essas ideias e traduz as mais promissoras de todas em planos de negócios. A terceira etapa concretiza os melhores planos de negócios, criando spin-offs. Já a quarta etapa consolida e fortalece o valor econômico criado por intermédio da empresa. $\mathrm{Ou}$ seja, constitui-se em estratégias para a manuntenção e crescimento dessas empresas na região onde foram geradas, com vistas ao desenvolvimento econômico e social daquela localidade.

Segundo Di Gregório e Shane (2003 apud PEREIRA, 2007), pesquisadores de alta qualidade têm maior probabilidade de explorar os resultados de sua pesquisa. Ainda, universidades de prestígio ou reputação facilitam a geração de spin-offs, devido ao fato de investidores acreditarem que tecnologias geradas em universidades de ponta têm maior garantia de sucesso.

Através de um estudo de caso realizado em uma universidade pública brasileira, Azevedo (2005) salientou que as principais motivações para a criação de empresas pelos pesquisadores são: a satisfação em colocar à disposição da sociedade os resultados de suas pesquisas e a possibilidade de obter bons retornos financeiros. Porém, algumas barreiras como a necessidade de um contínuo desenvolvimento tecnológico e a falta de capacitação gerencial são encontradas pelos pesquisadores que decidem criar uma empresa. Além disso, há poucos incentivos no meio acadêmico para a formação de spin-offs, seja pelo excesso de burocracia, seja também pela falta de legislação mais clara quanto à propriedade intelectual.

Azevedo (2005) observou ainda que a criação de spin-offs beneficia toda a sociedade ao oferecer-lhe produtos e serviços cujos conhecimento e tecnologia são frutos de pesquisas realizadas nas universidades. Além disso, as empresas criadas geram empregos, em que prevalece o alto nível de qualificação. Entretanto, para se constituírem, os spin-offs necessitam de suporte. Isso pode ocorrer via instalação em uma incubadora ou por meio de programas públicos de incentivos.

Os ganhos de competitividade que a inovação pode trazer são importantes estímulos para a implementação de produtos e, ou, processos novos ou substancialmente aprimorados pela empresa. De acordo com a Pesquisa de Inovação Tecnológica (Pintec) realizada pelo Instituto Brasileiro de Geografia e Estatística (IBGE), com o apoio da Financiadora de Estudos e Projetos (FINEP), o percentual de indústrias brasileiras inovadoras cresceu $21 \%$ nos últimos oito anos. Conforme a pesquisa (IBGE, 2010):

- No ano 2008, de um universo em torno de 106,8 mil empresas, cerca de 41,3 mil implementaram produto e, ou, processo novo ou substancialmente aprimorado de 2006 a 2008. Comparando esses números com os da Pintec 2005, em que o universo era de 95,3 mil empresas, sendo 32,8 mil inovadoras, pôde-se observar aumento na taxa de inovação de 34,4\% no período 2003-2005 para 
$38,6 \%$ de 2006 a 2008.

- Os recursos humanos envolvidos com as atividades internas de P\&D totalizaram aproximadamente 73,3 mil pessoas ocupadas nessa atividade, sendo 48,1 mil nas empresas industriais, 18,2 mil nas de P\&D e 7 mil nas empresas dos serviços selecionados (IBGE, 2010).

$\mathrm{Na}$ Pintec 2005, 84,5\% das empresas inovadoras pertencentes ao âmbito da pesquisa apontaram, ao menos, impacto proveniente da inovação como relevante (alto ou médio). Em relação às empresas inovadoras do período 20062008, esse percentual aumentou para $88,3 \%$, indicando que maior número de empresas que realizaram inovação de produto e, ou, processo obteve impactos significativos dela provenientes.

Comparando o percentual de empresas inovadoras que utilizaram ao menos um instrumento de apoio governamental de 2003-2005 com o resultado observado no período de 20062008, concluiu-se que houve aumento nessa participação de $18,8 \%$ para $22,3 \%$. Assim, atingiuse o número de cerca de 9,2 mil empresas que utilizaram algum incentivo público federal para inovar de 2006 a 2008 (IBGE, 2010).

\section{Metodologia de pesquisa}

Os métodos de pesquisa podem ser classificados com base na forma de obtenção dos dados. Entre os principais estão: estudos de caso, experimentais e levantamento de dados por meio de histórico ou análise de informações de arquivos. Este trabalho trata-se de uma pesquisa qualitativa, tendo como método o estudo de caso, sendo desenvolvida no local onde ocorria o fenômeno, conhecendo o seu ambiente, suas funções básicas e a forma de gerenciá-lo, possuindo, assim, caráter de profundidade e detalhamento. Quando o estudo de caso é bem planejado, pode ser um desafio relevante para uma teoria e, ao mesmo tempo, ser a fonte de novas hipóteses e constructos (VERGARA, 2005).

O desenvolvimento deste trabalho consistiu num estudo de caso que teve por objetivo geral estudar o desempenho de empresas de base tecnológica de origem acadêmica, as chamadas spin-offs acadêmicas. As empresas analisadas representam a amostra daquelas que participaram do programa de incubação da Incubadora de Empresas de Base Tecnológica do Centro
Tecnológico de Desenvolvimento Regional de Viçosa, da Universidade Federal de Viçosa (IEBT/CENTEV/UFV). A amostra da pesquisa foi constituída de $20 \%$ do total de empresas graduadas.

Primeiramente foram identificadas e analisadas as empresas que participaram do programa de incubação e posteriormente graduado. Em seguida, aplicou-se um questionário para obtenção dos dados de interesse da pesquisa.

Através de um questionário estruturado (Anexo A), as empresas responderam sobre informações gerais, situação técnica e financeira, gestão de pessoas e investimentos em P\&D. As empresas foram classificadas quanto ao seu tamanho, localização, setor de atividade, esforços em P\&D, captação de recursos etc. As informações foram analisadas no período compreendido entre 2007 e 2009.

\section{Análise dos resultados}

A Incubadora de Empresas do CENTEV foi criada em 1996. Desde então, essa empresa já graduou 24 empresas de base tecnológica. Atualmente, a incubadora possui 18 empresas incubadas e seis projetos de negócios préincubados. O número de empregos gerados pelas empresas incubadas vem aumentando (Figura 1), em razão do número de empresas graduadas. Durante os últimos anos, as empresas incubadas aumentaram, de forma significativa, seu faturamento bruto, com exceção do período referente à crise mundial de 2008, conforme ilustrado na Figura 2. No ano 2010, a soma do faturamento bruto das empresas incubadas foi de aproximadamente $\mathrm{R} \$ 1,6$ milhão, enquanto as empresas graduadas foram de $\mathrm{R} \$ 3,5$ milhões. Os impostos pagos pelas empresas incubadas em 2009 totalizaram uma arrecadação de aproximadamente $\mathrm{R} \$ 193.000,00$.

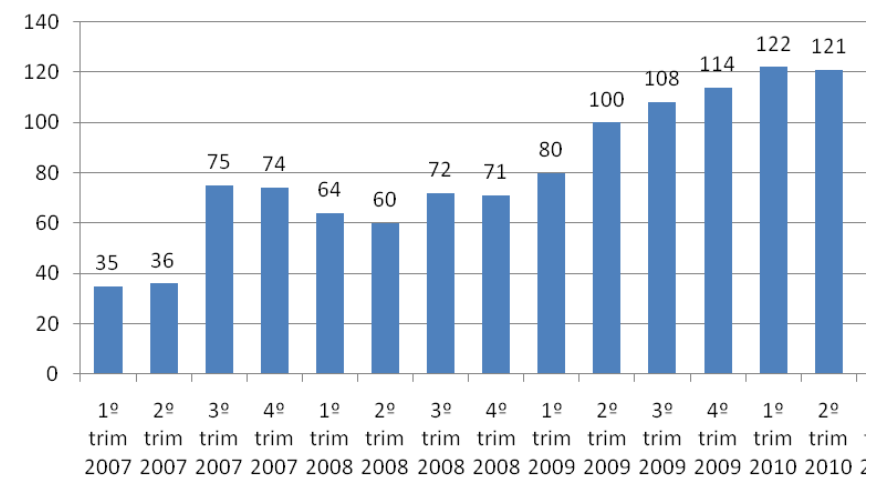

Figura 1 - Postos de trabalho gerados pelas empresas incubadas 


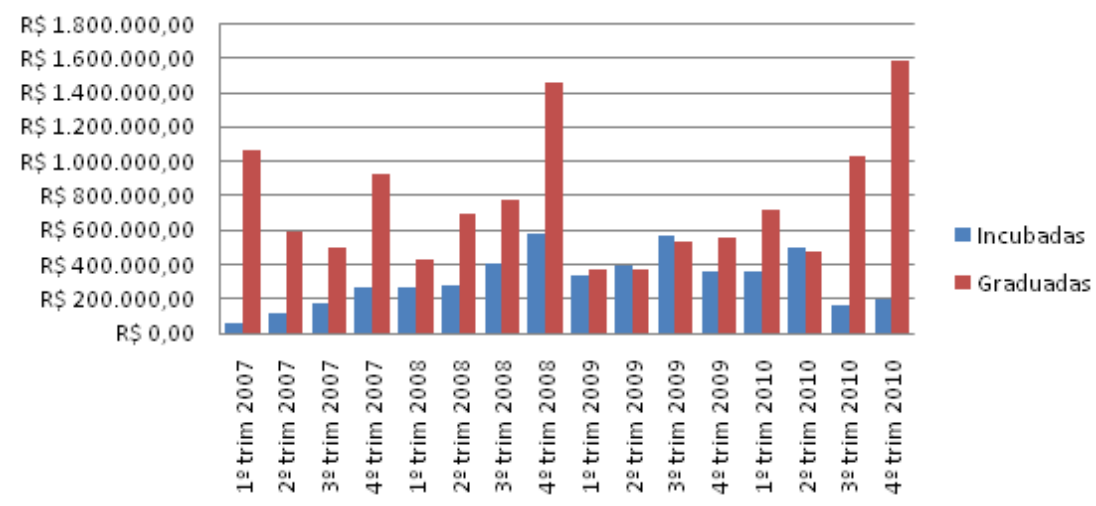

Figura 2 - Postos de trabalho gerados pelas empresas incubadas e graduadas

Entre as empresas graduadas pela Incubadora de Empresas de Base Tecnológica CENTEV/UFV, 16 podem ser caracterizadas como spin-offs acadêmicas, e cerca de $20 \%$ delas participaram da pesquisa realizada neste estudo. Essas empresas atuavam em setores como tecnologia da informação, agronegócio, energético, florestal, publicidade e propaganda.

A arrecadação de impostos das spin-offs entrevistadas em nível federal teve, em média, um crescimento de $230 \%$ entre os anos 2007 a 2009, sendo de $\mathrm{R} \$ 20.578,49$ em 2007, R $\$ 65.794,34$ em 2008 e R\$69.972,97 em 2009, conforme apresentado na Figura 3. No tocante aos impostos municipais, observou-se oscilação na arrecadação média do período, variando de $\mathrm{R} \$ 2.646,49 \mathrm{em}$ 2007, R\$6.344,59 em 2008 e $\mathrm{R} \$ 4.718,96$ em 2009, conforme mostrado na Figura 4.

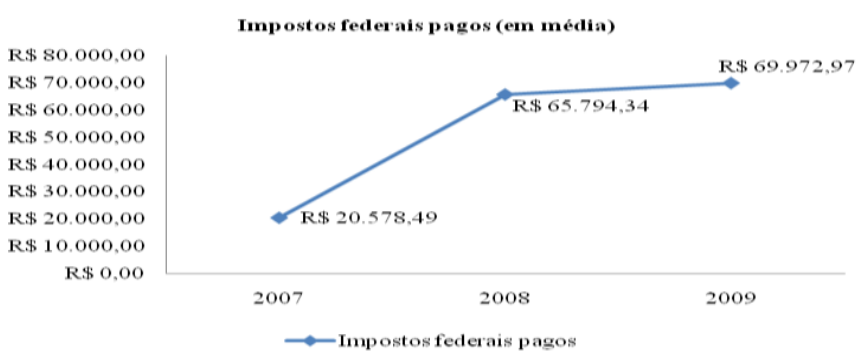

Figura 3 - Impostos federais pagos pelas spin-offs avaliadas

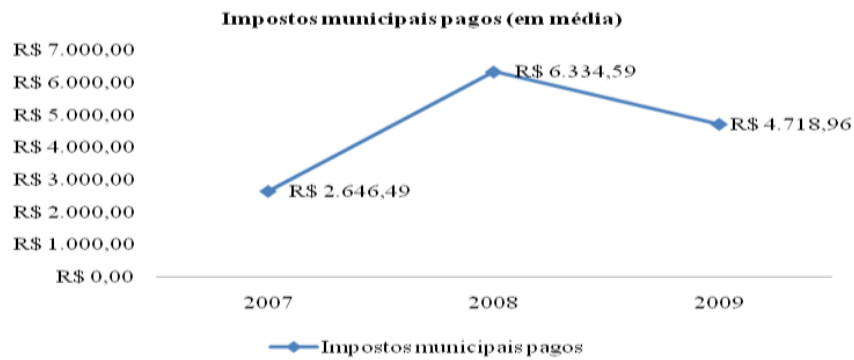

Figura 4 - Impostos municipais pagos pelas spin-offs avaliadas
$\mathrm{Na}$ pesquisa, as empresas declararam possuir, em média, 10 funcionários no período em questão, recebendo um salário médio em torno de $\mathrm{R} \$ 2.100,00$. Isso mostra que o nível de qualificação empregado nessas empresas é alto, se comparado com a média salarial praticada no universo onde estão inseridas, onde a média em Minas Gerais é de $\mathrm{R} \$ 1.223,47$ e no Brasil, de $\mathrm{R} \$ 1.494,66$, no ano 2008, segundo pesquisa RAIS do Ministério do Trabalho e Emprego (2008).

Através desses dados, ressalta-se a importância das empresas de base tecnológica como promotora do desenvolvimento social. Essas empresas, além de contribuírem para a arrecadação de impostos tanto na esfera nacional quanto na esfera local, são geradoras de emprego com um nível salarial diferenciado.

Das empresas entrevistadas, $70 \%$ possuíam registro de Propriedade Intelectual. Os investimentos de capital estatal em P\&D também são utilizados para trazer inovação a essas organizações; e o valor também é bem expressivo, totalizando uma verba de $\mathrm{R} \$ 407.400,00$.

No universo de empresas estudadas, foi escolhida para uma análise mais detalhada a empresa " $A$ ", pelo fato de que ela indicou melhores resultados em relação aos demais. O total de impostos pagos pela empresa "A" supera a média global dos impostos pagos pelas empresas, conforme mostrado nas Figuras 5 e 6 . Essa organização recebeu recursos de fomento e de licitações públicas. São valores bem expressivos, levando em conta o tamanho e porte da organização. Os valores de licitações públicas foram de $\mathrm{R} \$ 94.310,79$ em 2008 e $\mathrm{R} \$ 273.517,60 \mathrm{em}$ 2009. A empresa estudada também recebeu recursos de fomento $\mathrm{P} \& \mathrm{D}$ das seguintes instituições: Finep, Fapemig e CNPq, totalizando 
$\mathrm{R} \$ 87.900,00$ em 2007, R\$192.400,00 em 2008 e $\mathrm{R} \$ 215.000,00$ em 2009.

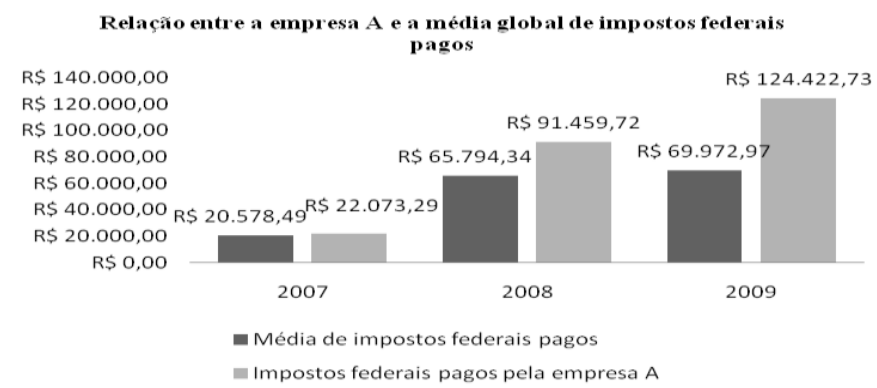

Figura 5 - Impostos federaias pagos pela spin-off "A" avaliada

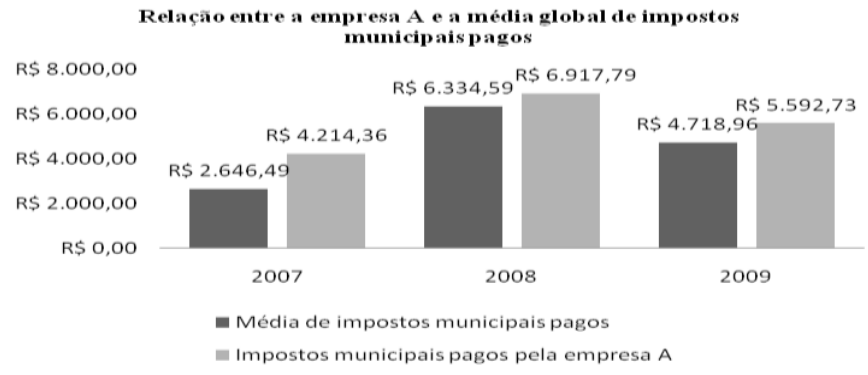

Figura 6 - Impostos municipais pagos pela spin-off "A" avaliada

Essa tendência de crescimento da empresa "A" é verificada também através do número de funcionários, mostrando a superioridade desta em relação às outras empresas que responderam aos questionários (Figura 7).

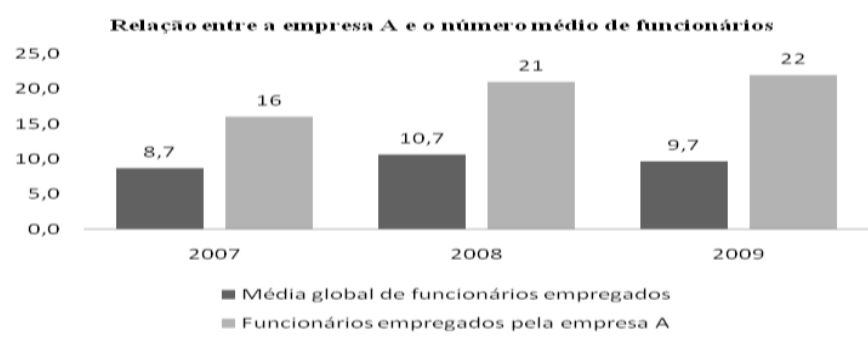

Figura 7 - Relação entre a empresa A e o número médio de funcionários

Assim, através desses dados, é possível observar que os órgãos de fomento são importantes aceleradores de empresas. A empresa A superou a média das demais empresas em todos os indicadores citados. Pôde-se observar um ciclo, em que os editais de fomento promovem o crescimento da empresa, que se desenvolve e, consequentemente, paga mais impostos para $\mathrm{o}$ governo e gera mais empregos para uma região.

\section{Conclusão}

Apesar da simplicidade dos resultados, através deste estudo percebeu-se a importância das ENBTs para o desenvolvimento local, por intermédio do potencial de crescimento das empresas de base tecnológica, gerando empregos e contribuições fiscais. É relevante também o papel das incubadoras dessas empresas no desenvolvimento dessas organizações, com o apoio operacional e gerencial, assim como a importância dos órgãos de fomento e recursos públicos no investimento em P\&D para o desenvolvimento das ENBTs. A empresa que mais recebeu recursos de órgãos de fomento foi a empresa que mais cresceu, superando a média em todos os indicadores, em comparação com as demais empresas.

Destaca-se a importância da inovação e da tecnologia como fatores cruciais para o desenvolvimento econômico e industrial, sendo os principais responsáveis pela geração de conhecimento as universidades, através da pesquisa científica; as empresas, através da capitalização do conhecimento, gerando emprego e contribuições fiscais; e o governo, através de incentivos fiscais e fomento.

\section{Referências}

ANPEI. Disponível em: <http://www.anpei.org.br>.

ANPROTEC. Disponível em: 〈http://www.anprotec.org.br>. Acesso em: 23 nov. 2010.

ARAÚJO, M. H.; LAGO, R. M.; OLIVEIRA, L. C. A.; CABRAL, P. R. M.; CHENG, L. C.; BORGES, C.; FILION, L. J. Spin-off acadêmico: criando riquezas a partir de conhecimento e pesquisa. Química Nova, v. 28, p. s23-s35, 2005. Suplemento.

AZEVEDO, G. C. O. Transferência de tecnologia através de spin-offs: os desafios enfrentados pela UFSCAR. 2005. Dissertação (Mestrado em Engenharia de Produção) Universidade Federal de São Carlos, São Carlos, SP, 2005.

CHENG, L. C.; FILHO, L. D. R. M. QFD - Desdobramento da função qualidade na gestão de desenvolvimento de produtos. São Paulo: Blucher, 2007.

COSTA, L. B. Criação de empresas como mecanismo de cooperação universidade-empresa: os spin-offs acadêmicos. 2006. Dissertação (Mestrado em Engenharia de Produção) Universidade Federal de São Carlos, São Carlos, SP, 2006.

COSTA, L. B.; TORKOMIAN, A. L. V. Spin-off acadêmico: mecanismo de transferência tecnológica de universidades para a sociedade. In: ENCONTRO NAC. DE ENG. DE PRODUÇÃO, 25., 2005, Porto Alegre. Resumos... Porto Alegre, 2005.

DORNELAS, J. C. A. Planejando incubadoras de empresas: como desenvolver um plano de negócios para 
incubadoras. Rio de Janeiro: Campus, 2002.

FARIA, A. F.; CHENG, L. C. Plano tecnológico estendido para empresas nascentes de base tecnológica. Viçosa, MG: UFV, 2008. (Projeto de pesquisa).

IBGE. Pesquisa de inovação tecnológica 2008 - PINTEC 2008. Rio de Janeiro, 2010.

LEMOS, L. M. Desenvolvimento de spin-offs acadêmicos: estudo a partir do caso da UNICAMP. 2008. Dissertação (Mestrado em Política Científica e Tecnológica) Universidade Estadual de Campinas, Campinas, SP, 2008.

LIMA, A. P.; LEITE, P. A.; FILHO, S. J. M. S. Método para promoção de spin off de projeto de pesquisa acadêmica de base tecnológica. In: SEMINÁRIO NACIONAL DE PARQUES TECNOLÓGICOS E INCUBADORAS DE EMPRESAS, 19., 2009, Florianópolis. Resumos... Florianópolis, 2009.

MINISTÉRIO DO TRABALHO E EMPREGO. Relação anual de informações sociais. Disponível em: <http://www.mte.gov.br>.

MUSTAR, P.; RENALT, M.; COLOMBO, M. G.; PIVA, E.; FONTES, M.; LOCKETT, A.; WRIGHT, M.; CLARUSSE, B.; MORAY, N. Conceptualising the heterogeneity of research-based spin-offs: A multi-dimensional taxonomy. Elsevier: Research Policy, 2006.

NDONZUAU, F. N.; PIRNAY, F.; SURLEMONT, B. A stage model of academic spin-off creation. Technovation, v. 22, p. 281-289, 2001.

PEREIRA, L. B. Processo empreendedor de spin-offs universitárias - Principais fatores determinantes. 2007. Dissertação (Mestrado em Administração) - Universidade Federal de Minas Gerais, Belo Horizonte, 2007.

REIS, L. P. Um modelo para o gerenciamento de informações no processo de planejamento tecnológico aplicado a um spin off do setor de biotecnologia. 2007. Dissertação (Mestrado em Engenharia de Produção) Universidade Federal de Minas Gerais, Belo Horizonte, 2007. 
ANEXOA

QUESTIONÁRIO APLICADO ÀS EMPRESAS GRADUADAS NA INCUBADORA DE EMPRESAS DE BASE TECNOLÓGICA CENTEV/UFV

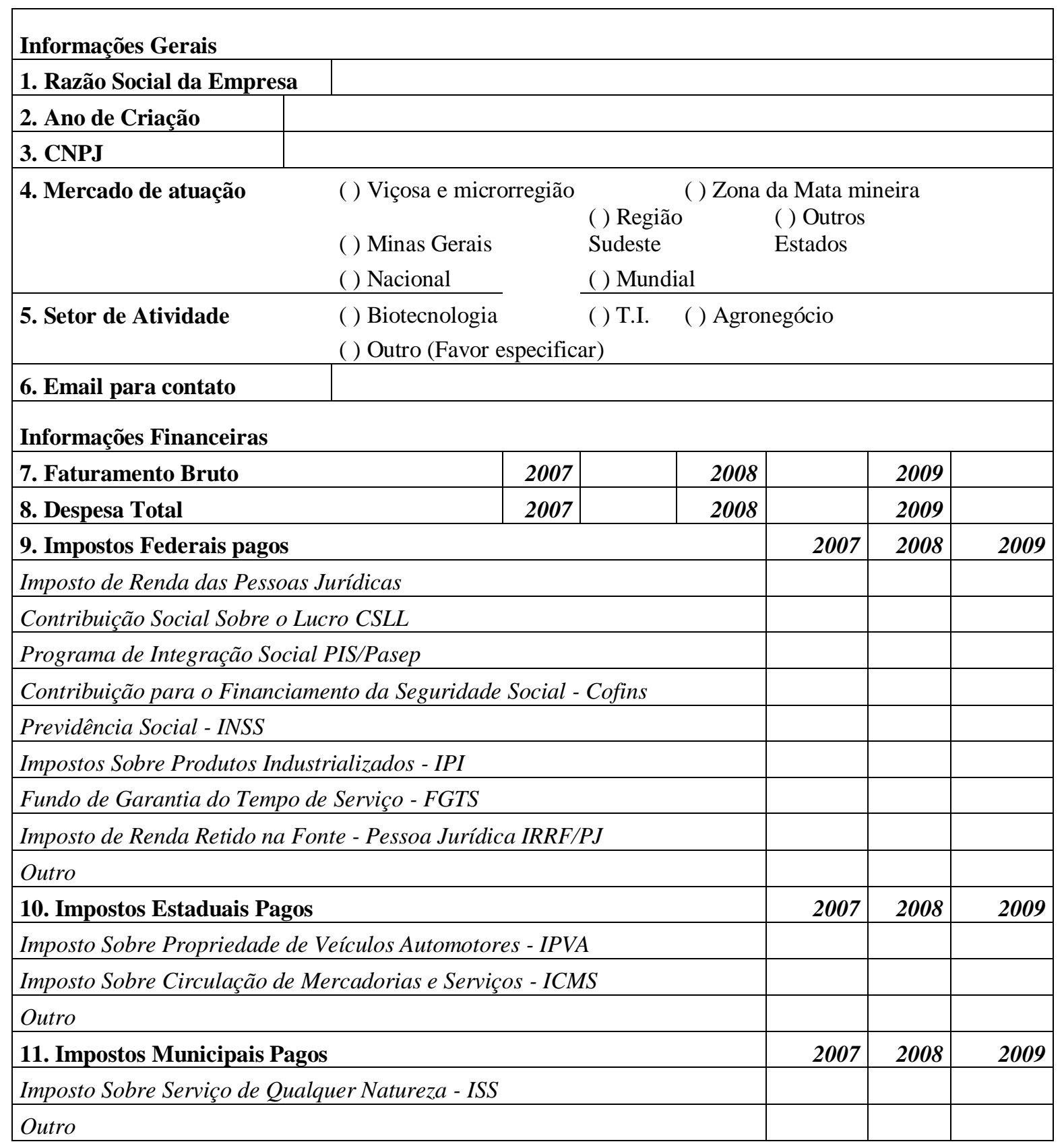


Gestão de Pessoas

12. Número de Funcionários

13. Salário Médio

14. Número de Bolsistas

15. Valor Médio do Benefício de Bolsistas

16. Número de Estagiários

17. Valor Médio do Benefício aos Estagiários

18. Número de Sócios

19. Média da Retirada Pro Labore

20. Empregos Indiretos Criados

\begin{tabular}{|c|c|c|c|}
\hline & & Ano de Criação & 2007 \\
\hline & & 2008 & 2009 \\
\hline & 2007 & 2008 & 2009 \\
\hline & 2007 & 2008 & 2009 \\
\hline Bolsistas & 2007 & 2008 & 2009 \\
\hline & 2007 & 2008 & 2009 \\
\hline Estagiários & 2007 & 2008 & 2009 \\
\hline$\cdot e$ & & & \\
\hline & 2007 & 2008 & 2009 \\
\hline
\end{tabular}

Investimentos em Pesquisa e Desenvolvimento

21. Recebeu Recursos de Processo de Licitação Pública

22. Valor Recebido de Licitação Pública

2007

( ) $\mathrm{Sim}$

( ) Não

23. Recebeu Recursos de Fomento

24. Órgãos ou Instituições que concederam o Benefício

\begin{tabular}{|l|l|r|r|r|}
\hline & Ano de Criação & 2007 & 2008 & 2009 \\
\hline CNPq & & & & \\
\hline FAPEMIG & & & & \\
\hline BNDEP & & & & \\
\hline Outros & & & & \\
\hline
\end{tabular}

25. Recebeu Recursos de Fundo de Capital de Risco

26. Valor Recebido de Fundo de Capital de Risco

2007
( ) $\mathrm{Sim}$

( ) $\operatorname{Sim}$
2009

( ) Não

27. Descrição de Novos Produtos/Serviços Gerados

$$
\begin{array}{|l|}
\hline \text { I. } \\
\hline \text { II. } \\
\hline \text { III. } \\
\hline \text { IV. } \\
\hline \text { V. } \\
\hline \text { VI. } \\
\hline
\end{array}
$$

28. Investimentos em P\&D com Recursos Próprios

29. Investimentos em Outros Setores (produção, comercialização etc.)

\begin{tabular}{|c|c|}
\hline Ano de Criação & 2007 \\
\hline 2008 & 2009 \\
\hline Ano de Criação & 2007 \\
\hline 2008 & 2009 \\
\hline
\end{tabular}

30. Possui Registro de Propriedade Intelectual

( ) $\mathrm{Sim}$

( ) Não 
Bárbara E. C. Minardi, Flávio L. M. Vita, Jaqueline A. Suzuki, Frederico S. L. B. Souza e Adriana F. Faria

\begin{tabular}{|l|l|}
\hline 31. Modalidades de Propriedade Intelectual \\
\hline () Propriedade industrial: Patente $n^{o}$ : & \\
\hline () Propriedade industrial: Marca $n^{o}$ : & \\
\hline () Propriedade industrial: Desenho industrial $n^{o}$ : & \\
\hline () Propriedade industrial: Indicação Geográfica $n^{\circ}:$ & \\
\hline () Cultivares & \\
\hline () Programas de Computador & \\
\hline () Direitos Autorais & \\
\hline () Outro (Favor Especificar) & \\
\hline 32. Interesse em instalar-se no Parque Tecnológico de Viçosa CENTEV/UFV. (Favor justificar) \\
\hline
\end{tabular}

Artigo selecionado entre os 10 melhores do VII Encontro Mineiro de Engenharia de Produção EMEPRO 2011. 